\title{
Architecture_MPS
}

Interview article

\section{Driving on the Left: Sorkin's View of the Street, the City and architecture}

Michael Sorkin ${ }^{1}$, Graham Cairns ${ }^{2, *}$

How to cite: Sorkin, M., Cairns, G. 'Driving on the Left: Sorkin's View of the Street, the City and architecture.' Architecture_MPS, 2013, 2(1): 4, pp. 1-13. DOI:

https://doi.org/10.14324/111.444.amps.2013v2i4.001.

Published: 01 April 2013

\section{Peer Review:}

This article has been peer reviewed through the journal's standard Editorial double blind peer review.

\section{Copyright:}

(C) 2013, The Author(s). This is an Open Access article distributed under the terms of the Creative Commons Attribution License (CC-BY) 2.0 https://creativecommons.org/licenses/by/2.0/, which permits re-use, distribution and reproduction in any medium, provided the original author and source are credited • DOI: https://doi.org/10.14324/111.444.amps.2013v2i4.001

\section{Open Access:}

Architecture_MPS is a peer-reviewed open access journal.

*Correspondence: gc@architecturemps.com

${ }^{1}$ Bernard and Anne Spitzer School of Architecture, City College of New York, City University of New York (CUNY), USA

${ }^{2}$ AMPS (Architecture, Media, Politics, Society) 


\title{
Title: Driving on the Left: Sorkin's View of the Street, the City and architecture
}

\author{
Michael Sorkin
}

Interviewer / author - Graham Cairns

Research - Rachel Isaac-Menard

Architecture_media_politics_society. vol.2, no.4.

April 2013

Affiliation: Bernard and Anne Spitzer School of Architecture, City College of New York, City University of New York (CUNY)

\begin{abstract}
:
Sardonic, cutting, insightful, provocative: Michael Sorkin is one of today's most radical architectural commentators with a staunch leaning to the political left and a literary bent for framing painful truths in ironic, and sometimes hilarious, verse. However, he should not be dismissed as a radical, isolated, or lone and unhindered voice however. He is a Distinguished Professor of Architecture and Director of the Graduate Program in Urban Design at the City College of New York, and he has been Professor of Urbanism and Director of the Institute of Urbanism at the Academy of Fine Arts, Vienna. In addition, he has taught at architecture schools across the world, including the Architectural Association, Columbia, Yale, Harvard and Cornell. Sorkin runs his own design studio and research institute and has been a contributing editor of the Architectural Record. He was the architecture critic of the Village Voice for ten years and has published innumerable articles and essays.

A list of some of his books includes: Twenty Minutes in Manhattan, Variations on a Theme Park, Exquisite Corpse, The Next Jerusalem, Indefensible Space, and a long list of other etcs. and alsos....In this interview-article, he offers his opinion on a range of issues, including the environmental threats to contemporary America, architectural symbolism and paranoia, the importance of political action on the streets of the modern city, and the role of the architecture critic in the complex tapestry of contemporary culture. With regard the position of the modern critic, he begins by responding to a question regarding the relevance of Noam Chomsky's description of the media as a form of propaganda and the contemporary journalist as functioning through the structure of what Chomsky defines as "filters," or constraints and biases that dictate what gets written and published in the press.
\end{abstract}




\title{
Title: Driving on the Left: Sorkin's View of the Street, the City and architecture
}

\author{
Michael Sorkin
}

Interviewer / author - Graham Cairns

Research - Rachel Isaac-Menard

Architecture_media_politics_society. vol.2, no.4.

April 2013
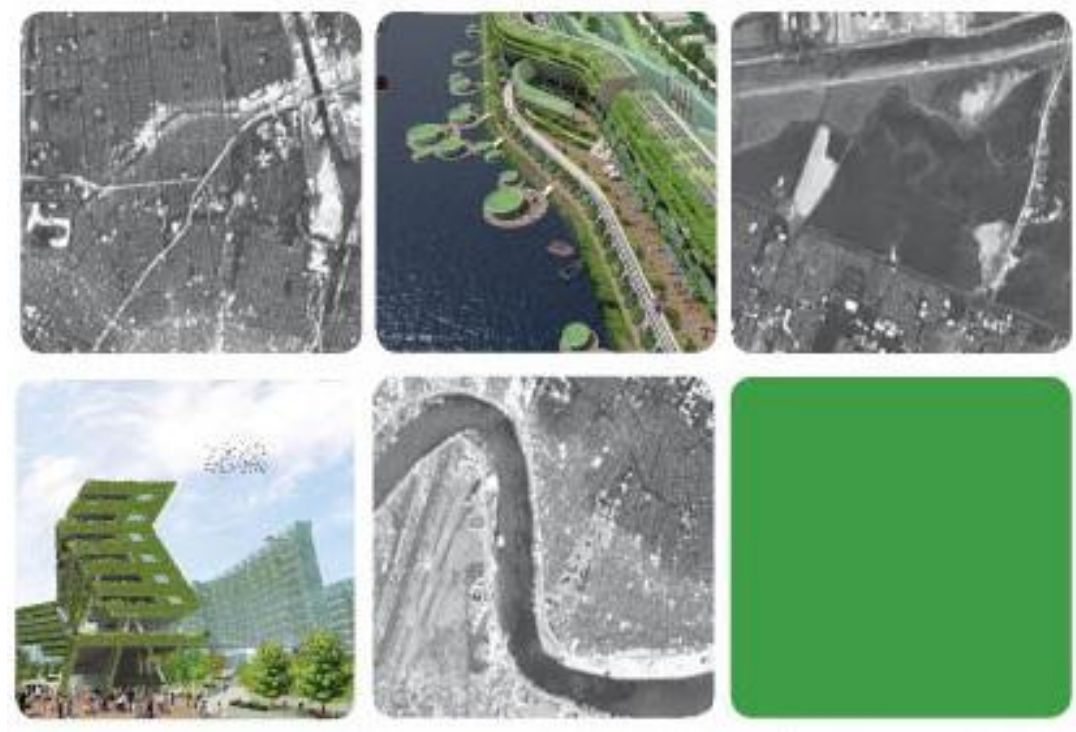

Terreform, book cover for "New Algiers"

Sardonic, cutting, insightful, provocative: Michael Sorkin is one of today's most radical architectural commentators with a staunch leaning to the political left and a literary bent for framing painful truths in ironic, and sometimes hilarious, verse. However, he should not be dismissed as a radical, isolated, or lone and unhindered voice however. He is a Distinguished Professor of Architecture and Director of the Graduate Program in Urban Design at the City College of New York, and he has been 
Professor of Urbanism and Director of the Institute of Urbanism at the Academy of Fine Arts, Vienna. In addition, he has taught at architecture schools across the world, including the Architectural Association, Columbia, Yale, Harvard and Cornell. Sorkin runs his own design studio and research institute and has been a contributing editor of the Architectural Record. He was the architecture critic of the Village Voice for ten years and has published innumerable articles and essays.

A list of some of his books includes: Twenty Minutes in Manhattan, Variations on a Theme Park, Exquisite Corpse, The Next Jerusalem, Indefensible Space, and a long list of other etcs. and alsos... ${ }^{1}$ In this interview-article, he offers his opinion on a range of issues, including the environmental threats to contemporary America, architectural symbolism and paranoia, the importance of political action on the streets of the modern city, and the role of the architecture critic in the complex tapestry of contemporary culture. With regard the position of the modern critic, he begins by responding to a question regarding the relevance of Noam Chomsky's description of the media as a form of propaganda and the contemporary journalist as functioning through the structure of what Chomsky defines as "filters," or constraints and biases that dictate what gets written and published in the press. ${ }^{2}$

I am a relatively marginal critic and, in that sense, I have the luxury of operating somewhat independently of the forces you've identified with Chomsky's critique, but I obviously don't operate outside of the culture. In that context, if you were to produce a theory of constraint, I think you'd have to look not simply at the producers of news and criticism, but also at consumers. There is a mutual relationship between production and consumption: the invention of desire isn't simply passive. The bigger question is of the space into which critical interventions to challenge this can be directed. I am not sure that a theory that simply suggests there is repression on one side and innocence on the other quite covers the situation. ${ }^{-3}$ Culture is a little more complicated than that.

For sure, we live at a moment in which star fucking is the national pastime and we are drowning in the cult of empty celebrity, but you cannot lay that exclusively at the door of the media: values have complex origins. ${ }^{4}$ As I said, a theory of democracy in which one side is free and the other perfectly constrained doesn't really cut it. These are very big questions and demand broad attention to the production of readers. In the States - with its appalling primary and secondary education and ubiquitous attention-contracting digital environment - we are failing to produce a wide body of general readers, of consumers of a criticism that exceeds advice about consumption. ${ }^{5}$ For better and worse, the media in which I transmit my opinions are mainly directed to elites - whether I am talking to the already convinced left, to aesthetes who really care about architecture, or to environmentalist fellow-travellers. Writing in the architecture journals, this is a more telling constraint, perhaps, than that other set of cultural filters - not that they don't operate.

The Ground Zero competition, to take one example, was played out in the press as a media spectacle. ${ }^{6}$ It very quickly dismissed the possibility of doing anything other than reconstructing ten million square feet of office space. That became the default position of nearly everybody, including the New York Times. There were other voices - I wrote a book about it at the end ${ }^{7}$ - but the constituency for the no-build possibility was mainly the survivor groups and, irony of ironies, Rudy Giuliani. ${ }^{8}$ The process was covered extensively in the Times by Herbert Muschamp, but his indifference to these issues did not simply reflect a journalist toeing the line or his subjugation to real estate interests. He was just not very interested in questioning the deeper social and economic assumptions of the project. $^{9}$

Herbert was ever too much in love with fashion and glamour. I think he authentically believed in it and its capacity to 


\section{Amps}

assume real content - he thrilled to it. He was a smart guy and a gifted writer but very invested in the celebrity side of architecture. ${ }^{10}$ Happily, the new architecture writer at the Times is distinguishing himself for thinking about architecture as the embodiment of social forces and as an agent for progressive change. He's pretty scrupulously trying to invent himself as the anti-Herbert and that is progress, although he gets flack from architects who expect "coverage" of their latest projects. ${ }^{11}$ I still write periodically myself. I wrote regularly for one of the architectural magazines until recently, but I am tired of writing exclusively for that audience, and, since the Village Voice, I have never really had an opportunity to write regularly for a broader public. ${ }^{12}$ Now I am devoting myself to writing books and to my architectural practice, although I am just about to jump back in with columns for an architectural and a political magazine.

\footnotetext{
Questioned on his practice and its involvement in urban design in China, Sorkin is presented with the conundrum of the constraints and restrictions imposed on design in that context - a context in which the speed of development sees cities built in months and results in deadlines that are sometimes only met through cutting corners in design. His practice, Michael Sorkin Studio, has a focus on issues of sustainability, 13 and he is asked to comment on the lethargy of U.S. industry in developing green technologies and responding to environmental issues. In response, he offers comments on recent environmental events and the role and response of government in dealing with these events and developing solutions in conjunction with the design and building industries. As always, his comments are laced with humour.
}

I am focused on the practice at the moment. I'm an urbanist and I'm getting old, so I really want to build half a dozen cities by the end of the month! But seriously, it is an incredibly important job to be designing these places in China, given the exponential rates of urban population growth and the miserable quality of most of what gets built. China is both amazing and dreadful and negotiating that gap is frustrating - but fascinating. We are doing projects on very tight schedules - housing schemes and office buildings and whatever else we can do. We are very focused on China at the moment. We have built a bit in Turkey recently, but we've been less successful in the U.S. ${ }^{14}$

This country has been slow with regard green design and technology, but even the best efforts of the West risk being defeated by the hyper-consumption of the Chinese and the Indians - who are going to burn all the coal that we now tell them not to use. It's a weird form of eco-colonialism, but our sins don't really diminish our collective global liability simply beg the question of fair accountability. The U.S. government has been less than aggressive, but we will see what Obama does anything now that the election is over. He had a very tentative start in environmental matters because he was running scared in his first administration and was worried about the power of the fossil fuel cabal and its lust that every form of carbon be licentiously extracted and burnt! $!^{15}$

However, industry in this country is beginning to respond - although we're never going to be the Denmark or Germany. But consciousness of global warming is growing dramatically here, especially as the result of a series of recent catastrophes. You and I are talking in the immediate wake of Hurricane Sandy. ${ }^{16}$ This is already engaging people with larger sets of environmental, infrastructural, urban, and architectural questions, and this discussion grows intense. It is likely to cost one hundred billion dollars to 


\title{
Amps
}

do the repairs from this single event, and this is a powerful goad for a fundamental reconsideration of the form of this city. ${ }^{17}$

Indeed, politicians are already talking with shocking enlightenment - if only as an actuarial matter because another hit like Sandy is simply unsustainable. The environmental agenda and planning issues are being discussed together, and they are completely inseparable. We must urgently reconsider large swathes of the city that are vulnerable, and there is now a serious conversation about the nature of the needed protection. This is much divided along not entirely productive lines between those who are the big corporate advocates of massive barriers, and those who support the softer technologies of wetlands and percolation schemes.

But few doubt that there are low-lying places in NYC that are un-protectable - if not technically, then surely economically. ${ }^{18}$ One defining issue for their future turns on whether the federal government continues to subsidise insurance against floods in areas at continuing risk. These places are going to get hit again and again, and climate change and its spawn - sea level rise and more frequent and energetic storms - harbinger recurrent disaster. We now seem to have a hundred-year storm every two years, and the idea of a permanent and accelerating cycle of destruction and rebuilding grows more and more ridiculous.

If insurance subsidies go, it will lead to the large-scale abandonment of low-lying areas. We spend massive amounts of money to both subsidise people to build houses in places that will get swept away, as well as the Sisyphean reconstruction of beaches and coastal zones. What is needed, though, is a more adaptive relationship with natural forces. We will see what happens here, but we now have the exciting possibility to reconfigure the morphology of the city in a very dramatic way. People have short attention spans in this country, so we will see how it ultimately turns out, but I think something is going to happen - particularly when the bills start coming in at this time of deficit.

\begin{abstract}
Sorkin's seemingly positive interpretation of the likely consequences of Hurricane Sandy with regard a shift in planning policy contrasts sharply with his comments about the architectural and urban planning developments that emerged post 9/11. In various texts on that subject, he was scathing of the whole "charade" of a competition that emerged at the time. $19 \mathrm{He}$ has also been critical of how the projects developed for that competition reverted quickly to type, in terms of the architectural development model employed in practically all the proposed projects.20 Questioned on this, and whether the increased interest in architectural and urban design issues that flourished in the immediate aftermath of the event has had any long terms effects of planning policy and attitudes in the city, he responds:
\end{abstract}

The destruction of the World Trade Center was an act of global terror but also an extremely localised event. Certainly, it was the occasion for a conversation about the role of architecture in making good, in healing, in acting as a therapeutic medium for this trauma. ${ }^{21}$ People became interested in architecture in a very precise way, but it did not, alas, become an the occasion for rethinking the nature of cities or considering more global conditions. It is difficult to say whether it has had longer-term consequences with 


\section{Amps}

regard to public engagement with debates on architecture, although there was surely a vigorous discussion at the time. Have you been down there to take a look at this dreck that they are building? There has not been a happy ending to that controversy.

New York City may be special because we have a particularly strong sense of community, of neighbourhoods, a powerful reflex of reaction, and a historic culture of resistance: there are a lot of organisations in this city that turn out to oppose various big plans. ${ }^{22}$ On the other hand, money talks and ultimately one all too often winds up on the losing end of these battles. It is true that, in a rarefied aesthetic sense, architecture in New York City is getting a bit better formally. On the other hand, the tenacious privileging of the rich is completely out of control. This condition is both general and growing; the Gini coefficient is more and more unfavourable to the poor. ${ }^{23}$ The income gap gets bigger and bigger. This is what Occupy Wall Street was all about. One percent of the people are controlling forty-three percent of the wealth ... and on and on and on ... and nothing seems to have stopped - or redirected this juggernaut of accumulation.

The situation is not completely bleak, though, and there are countervailing trends. There has been an amazing efflorescence of urban agriculture and a proliferation of locally organized DIY urban interventions. There is also lively contestation over who has rights to the street. We are now becoming a bicycle culture, and suddenly bike lanes are being wrested from the automobile system. The city has a particularly enlightened transportation commissioner at the moment. ${ }^{24}$ If you've been to Times Square you know the cars are gone, as they are at Herald Square and other sites. So the public is reclaiming, or repurposing, what is the largest area of public space in the city - the streets. ${ }^{25}$ It is something that is going on in parallel to this continued process of wealth concentration. The problem is to distribute these transformations equitably, and it is still very much the case that parks in rich neighbourhoods are far better maintained than those in poor ones.

\footnotetext{
In After the World Trade Cent, Michael Sorkin spoke about the potential conversion of the Ground Zero site into public space, as opposed to its reappropriation by private capital. This was also a theme touched upon in Starting From Zero and Indefensible Space. In the latter he talks of a form of "urbanism of risk avoidance" - of which the Ground Zero project will be the epitome. In Indefensible Space, he also describes the intervention of James Kallstrom, a former FBI director, in debates about the redevelopment of the World Trade Centre site. Kallstrom raised concerns over its "increased capacity of assembly." 26 Questioned on contemporary urban planning and architecture in this "climate of fear and control," Sorkin is drawn into conversation about the "symbolism of security" around architecture today, and the climate of violence in the United States more generally.
}

If you go to Ground Zero, you'll discover you cannot enter the memorial without going through a metal detector, getting sniffed by dogs, being eyed by baleful guards, and surveilled by security cameras. It's an exemplary site and, like an airport, it seems to be a kind of training school for paranoia. ${ }^{27}$ People are a little restive about this, so there is a bit of pushback. The Occupy Wall Street event engaged this directly by capitalising on an interestingly anomalous condition directly across the street. The demonstrators 


\section{Amps}

gathered in a park that was privately developed as a public benefit in exchange for a private one - the right to construct a bigger building next door ${ }^{28}$ The deal meant that the park was, in certain ways, outside the normal regulatory system for public spaces, to wit it was open twenty-four hours a day. That was one of the things Occupy cannily capitalised on, and it allowed them to stay there around the clock.

There have always been time and manner restrictions on assembly and these are interesting for contestation, for defining our "right to the city." The struggle is very real, if often invisible. Just down the street from here is a big building that has as the Passport Agency, a bunch of federal offices, and allegedly one of the branches of the secret gulag for holding terrorist "suspects." In one block alone, there are fifty to sixty CCTV cameras. ${ }^{29}$ It's a lovely Foucauldian situation in that you have absolutely no idea whether anybody is actually watching you. So I always walk down that block and give them the finger . . . so far I have had no trouble ... but we will see!

The example of the New Jersey Barrier discussed by Trevor Boddy in Indefensible Space certainly functioned as a symbol - as did the increased use of bollards and anti-tank planter boxes around buildings I discuss in the same book. ${ }^{30}$ It seemed that government was meant to have done something, and it had to be visible in order to be persuasive. The general presence of these things has certainly been ratcheted up, like all those cameras. At some level, it is a sop to the public but, on another, it becomes a sort of status symbol: my corporation is so important, we must defend ourselves against Al Qaeda. It is an obvious example of how it is impossible to articulate architecture as discontinuous from other cultural phenomenon, and part of the complex weirdness the authorities are using in their manipulations.

Turn on the television and inventory the mayhem. It strikes me, as a middle-aged Luddite who has never played a post-Pong video game, that the hours of violence that figure in the daily life of the average twelve-year-old are absolutely staggering and must surely contribute heavily in an ethical numbing of consciousness. Violence, of various sorts, can also manifest itself in architectural form. Take a look at gated communities. Take a look at our fetish for firearms and at the way in which our frequent mass murders seem to take place in the most seemingly benign environments. The gun is such a central cultural artefact that I cannot fully unpack its meanings, but our reactionary anti-statist culture is certainly one component: the need to protect ourselves against those black helicopters. My own view is that our founding in the land of another the an - Native Americans whose lives were so devalued that we simply slaughtered them at will - is a crucial point of origin. But this is another topic.

In my optimism, though, I basically subscribe to the Rush Limbaugh view on Obama that, now he has been re-elected, he will come out of the closet as a genuine radical, invite the Reverend Wright and Bill Ayres to the White House, cut the defence budget in half, and give us real socialised medicine. Let's hope so! I had a fairly serious fracture over the summer and was entertained by the healthcare system. My surgeries went well, but I'm still fighting with Dickensian insurance companies about the bill. How anybody could defend this system mystifies me. But that is another conversation we have been having post-Thomas Frank: why does the working class and those on the short end of the stick vote against their own self-interest so consistently ? $^{31}$

In bringing the question of social policy and the role of federal government into the life 
of everyday Americans, Sorkin touches on a another politically conflictive area of American politics. In a country which views central dictates of government with suspicion, and at times rancour, he is questioned on central government involvement in one of the country's most pressing architectural issues: housing - both social and urban and private and suburban. With regard suburbia and its origins, he covers ground he treads in more detail in Some Assembly Required: the construction of the National Defense Highway System and the conversion of America into an automobile state. He also moves on to an issue he covers in Variations on a Theme Park: the 1950s Walt Disney urban design experiment, the Experimental Prototype Community of Tomorrow (EPCOT).32 He is questioned on how this relates to the climate of fear he described earlier, and that which underpinned the construction of the National Defense Highway System in the Cold War to some extent. He is also pushed on the "aspirational" notions that underlie suburbia and the national U.S. psyche.

What has America been since the eighteenth century if not the Experimental Prototype Community of Tomorrow? The anti-urban strain in the American political discourse is historic - the romantic view of the ownership of an isolated increment of property - and is part of a conversation we have been having for 250 years. It has deep roots that we are constantly reminded of. Yet another biography of Thomas Jefferson has just been published, ${ }^{33}$ and he was surely a key progenitor of the ideal of the suburbs, the "ownership society," and the idea of escape (and a rifle to keep others away). Today, advertising has a role, but advertising is not just about identifying fears - it is about stoking desires. Both emotions have historical roots and we probably produce the anxieties - and the desires - we deserve.

Both fear and desire were at play when we were massively tearing down our public housing projects. This took place in the Reagan and Clinton administrations, and is even happening now is various guises including current efforts to insinuate market housing into public sites. ${ }^{34}$ What those Corbusian blocks were often being replaced with (though not necessarily on site) was New Urbanism - and there are some arguments for the down-scaling and greater sense of intimacy and comfort that come with such a shift. But where it doesn't work is in the correspondence between the image and the numbers. If ten thousand people lose their homes and HOPE VI, ${ }^{35}$ the federal program for providing more distributed, lowerdensity housing, only takes care of one thousand of them, that means nine thousand people are left homeless in the bargain. We got rid of those oppressive projects and we built a bit of somewhat more humane development. That is fine, but the big picture is onerous. Government has tried to resolve the problems of the poor by eliminating their homes.

\footnotetext{
Asked to expand on what was intended to replace the housing demolished in slum clearance, Sorkin focuses on the issue of suburbia and more recent attempts to remodel suburbia on more "urban" models. In this regard, he again focuses on an issue covered in his previous writings: Reaganville.36 In his response to the raising of these issues here, he homes in on New Urbanism in particular. Citing superficial attempts to reconfigure urban and suburban living templates that have been a major issue of U.S. planning since the era of Jane Jacobs, he also extends his comments to a more contemporary aspect of modern living - our ever increasing occupation of "virtual space" (a subject that he covers in Variations on a Theme Park). It is an issue he sees as problematic, and is one he highlights in a brief aside about the use of certain
} 
branded retail spaces in cities for Internet connections.37 Whilst being suspicious of the growing social disembodiment that technologies such as the Internet can induce, he sees a way out. This way out is signposted by recent political events in New York, London, Madrid, Cairo and elsewhere.

New Urbanism does arrogate some positive ideas - including walkable environments and transit-oriented development - and it is true that its work has always been a little more complicated and diverse than people like me have represented. ${ }^{38}$ Many of its progenitors (especially on the West Coast) were people committed to environmental issues, but, unfortunately, the organization was captured by a cadre that thought that style was central and that somehow traditional architecture would impute to its residents the characteristics of a particular ideal subject: yeomen inhabitants of New England towns of the early republic.

In fact, ninety-five percent of what they actually do is for the suburban upper middle classes. To be sure, what they have advanced is a slightly better version of the suburbs, but - despite palaver about mixed use - these are almost entirely residential communities. But the New Urbanists are symptomatic of a much broader change that is a product of the sixties generation more generally. We now have disposable income; we've been to Europe; we eat yogurt, recycle, ride bikes. As a result, in part, there is a reurbanisation of the United States, and cities - once held more or less uniformly in suspicion - are now coming back as objects of imaginative desire. This sensibility is having an effect on the suburbs (if hardly a transformative one), and, if nothing else, the idea of "urban" lifestyles is increasingly marketable, if only in being able to walk from Victoria's Secret to Ikea!

You've mentioned being in New York and using the free Wi-Fi in Starbucks. We were certainly happy for this possibility when we lost power during Sandy. But the ubiquity of virtual communications does have the power to remake our embodied relationship with the city and our citizen-neighbours. One might say that these technologies have the effect of suburbanizing the city by inscribing fresh distances between us and conducing a variety of alienation effects: everybody on the street seems to be talking to somebody far away. I don't know what these conversations are about but there are always three people on the phone in the elevator and their remote connections completely distort the nature of the intimacy and sharing of the space.

But there's an upside too: the possibility for new forms of social life and organisation that facilitates rather than negates the face to face. Occupy Wall Street was organised online, the same for the demonstrations outside St. Paul's Cathedral in London and for the decisive gathering of people on the streets of Spain and Egypt and Tunisia. If technology operates as a supplement to human activity, it's a boon and an expansion, but if it displaces authentic (I use this word advisedly) human interaction, then it's another matter. I do worry that these technologies risk dangerously disembodying us. ${ }^{39}$ Fortunately, if you spend three days in New York City, you know that there's an antidote: the life of the street, the hustle and bustle, the chance encounters, the adventure of sharing with the other, the possibility of the happy accident that's at the core of good city life. 
Architecture_MPS has developed a new genre of academic writing; the 'interview-article'. It is a variation on the interview genre in which theoretical background is added for the reader through extensive and discursive notation that expands on the arguments and references made by the interviewer or the interviewee. It is an explanatory / descriptive adaptation of the standard interview format that makes it a hybrid academic literary form.

This article is available on the agreed terms of open access. Users are allowed to read, download, copy, distribute, print, search, or link to the full texts of the articles in this journal without asking prior permission from the publisher or the author. This is in accordance with the BOAI definition of open access. Users are expected to fully cite and reference the sources of any material accessed under this agreement. The image used here is from the book cover for "New Algiers", Terreform.

\footnotetext{
${ }^{1}$ Michael Sorkin, Exquisite Corpse: Writing on Buildings (New York: Verso, 1991); Twenty Minutes in Manhattan (New York: Reaktion Books, 2009); Variations on a Theme Park: The New American City and the End of Public Space (New York: Hill \& Wang, 1992); Local Code: The Constitution of a City at 42 degrees North Latitude (New York: Princeton Architectural Press, 1996); Some Assembly Required (Minneapolis: University of Minnesota Press, 2001); The Next Jerusalem. New York: Monacelli, 2002); After the World Trade Center: Rethinking New York City (New York: Routledge, 2002); Indefensible Space: The Architecture of the National Insecurity State (New York: Routledge, 2007).

${ }^{2}$ Chomsky and Herman's "Propaganda Model" of the media suggests that news is "filtered" so as to prevent ideas that run against the interests of media conglomerates (owners, advertisers and government) from reaching print. These filters are in essence the factors that influence editorial decisions. They include: i) ownership; ii) dependence on advertising revenue; iii) the sourcing of information; iv) "flack" (official criticism or corporate boycotts); v) anti-communism (recently replaced by anti-terrorism). The need of editors to balance, placate and reinforce these agendas is, according to the "Propaganda Model," at the heart of understanding why what gets reported is reported. Edward S. Herman and Noam Chomsky, Manufacturing Consent: The Political Economy of the Mass Media. $2^{\text {nd }}$ edition. (New York: Pantheon Books, 2002 ), 1-36.

${ }^{3}$ In Manufacturing Consent, Herman and Chomsky counter this criticism of their approach by arguing that it is a mistake to conclude that viewing and reading figures, for example, offers a "true" reflection of preferences and freely made choices. They suggest that these figures reflect what has been made readily available and what is intensely promoted, rather than an uninfluenced public "preference." Ibid., xviii-xix.

${ }^{4}$ The celebrity nature of contemporary architecture has been an issue of debate for approximately two decades now. See: Julia Chance and Torsten Schmiedeknecht, eds, Fame and Architecture. (London: John Wiley and Sons, 2001).

${ }^{5}$ The issue of education standards in the U.S. and other countries of the "developed world" has been covered recently in a number of texts. For example: Kevin J. Flint and Nick Peim, Rethinking the Education Improvement Agenda: A Critical Philosophical Approach (London: Continuum, 2012). A recent significant reference text dealing with the role of "new managerialism" in falling standards is: Ian Hextall, Reconstructing Teaching: Standards, Performance and Accountability. (London: Routledge Falmer, 2000).

${ }^{6}$ This issue was discussed by Michael Sorkin in various texts. The most notable are: After the World Trade Center: Rethinking New York City (New York: Routledge, 2002); Starting From Zero (New York: Routledge, 2003).

${ }^{7}$ Specifically, Starting From Zero documents Sorkin's proposals for the redevelopment of the site whilst, simultaneously, charting the course of the official competition and the projects that worked through it.

${ }^{8}$ In After the world Trade Centre, Sorkin quotes Mayor Rudy Giuliani's farewell speech delivered at St. Paul's Chapel, next to the world Trade Centre Site, in which he says: "I really believe we shouldn't think of this site as a site for economic development . . . We have to be able to create something here that enshrines this forever and that allows people to build on it and grow from it. And it's not going to happen if we think about this in a very narrow way." Michael Sorkin, Starting From Zero. Ibid.,197.

${ }^{9}$ The selection of journalists for particular roles is, Herman and Chomsky suggest, part and parcel of the "Propaganda Model." The journalists' "internalisation" of the constraints, expectations and values of the media outlets that employ them is integral to the efficient and apparently natural functioning of the supposedly "free media" model. Edward S. Herman and Noam Chomsky, Manufacturing Consent (New York, Pantheon Books, 2002), 1x

${ }^{10}$ Sorkin wrote about Herbert Muschamp's role in the Ground Zero competition in Starting From Zero. In particular, he focused on the direct intervention and propagating of "alternatives" by the then-critic of the New York Times and on his championing of "preferred" options. See: Sorkin, Starting From Zero (New York: Routledge, 2003), 86-91. This use of the position of critic in a daily newspaper represented a type of direct intervention in a supposedly "democratic" process that would be defined as a manipulative use of the press for indirect "promotional" purposes by authors such as David Michie - in David Michie, Invisible Persuaders (London: Bantam Press, 1998) - and Edwin C. Baker - in Edwin C. Baker, Advertising and a Democratic Press (New Jersey: Princeton University Press, 1995).
} 
${ }^{11}$ The current architecture critic of the New York Times is Michael Kimmelman. Katharine Jose of the online news publication, Capital - that "investigates how New York works" - has pointed out that his first three pieces were on the topics of a progressive subsidized housing scheme in the Bronx and the future of Penn Station. This compares with the last three articles of his predecessor (and protégé of Herbert Muschamp), Nicolas Ouroussoff, whose last three pieces were on the CCTV building by Rem Koolhaas, the Vanke Centre in Shenzhen by Steven Holl, and Zaha Hadid's Opera House in Guangzhou. Katherin Jose. "How 'The New York Times' Controls Architecture Criticism in America, Whoever its Critics May Be," Capital, March 1, 2012, http://www.capitalnewyork.com/article/culture/2012/03/5376996/how-new-york-times-controlsarchitecture-criticism-america-whoever-i

${ }^{12}$ Many of Michael Sorkin's articles from the Village Voice were collected into a single volume in 1991: Sorkin, Exquisite Corpse.

${ }^{13}$ According to the website of Michael Sorkin Studio, recent projects of the practice include: "planning and design for a highly sustainable 5000unit community in Penang, Malaysia, master planning for Hamburg, Visselhoevede, Leipzig, and Schwerin, Germany, planning for a Palestinian capital in East Jerusalem and for the center of Shanghai, urban design in Leeds, England, campus planning at the University of Chicago and CCNY, studies of the Manhattan and Brooklyn waterfronts, housing design in Far Rockaway, Vienna, and Miami, a resort in the desert of Abu Dhabi, a park in Queens, New York, a group of houses in Coorg, India, and a very low-cost housing prototype for rural Alabama." "Profile," Michael Sorkin Studio, http://www.sorkinstudio.com/companyprofile.htm

${ }^{14}$ A collection of the studio's projects were brought together in a single volume in the late 1990s. Michael Sorkin, Michael Sorkin Studio: Works in Progress Series (New York: Monacelli Press, 1998).

${ }^{15}$ Obama's legacy on environmental issues in his first term is covered by Byron W. Daynes and Glen Saussman. They suggest that the administration has been more restricted domestically than internationally and that the internal dynamics of the relationship between the legislature and the executive branches of the U.S. system have been more problematic than domestic public opinion has been. The public, whilst "unenthusiastic," indicates through polls an awareness of and a desire for some policy change. Byron W. Daynes and Glen Saussman, "Environmental Policy and Global Climate Change," in The Obama Presidency: A Preliminary Assessment, eds. Robert P. Watson and Douglas M. Brattebo (New York: Suny Press, 2012).

${ }^{16}$ This interview took place in Michael Sorkin's New York studio in November 2012, approximately two weeks after Hurricane Sandy had devastated parts of New Jersey and caused serious economic damage and disruption across New York City.

${ }^{17}$ David W Chen, "Council Speaker Urges Stormproofing as the Civic Conversation Shifts," New York Times, November 13, 2012,, http://www.nytimes.com/2012/11/14/nyregion/council-speaker-quinn-urges-steps-to-protect-against-hurricanes.html?_r=0

${ }^{18}$ These issues have been dealt with extensively in various papers and in a limited number of book publications. See: Jeroen C. J. H. Aerts and W. J. Wouter Botzen, Flood-Resilient Waterfront Development in New York City: Bridging Flood Insurance, Building Codes, and Flood Zoning (Boston, Mass.: Blackwell Publishing, 2011).

${ }^{19}$ In Starting From Zero, Sorkin says: "I cannot help feeling that the whole process has been corrupted by a meagerness of vision and a vanishing and over-aestheticized sense of loss. There is something nauseating about the celebratory atmosphere that surrounds the act of 'closure,' about all the haste of it all, and about the wheeling and dealing that led up to it and continue as various parties vie for control of the site." Sorkin, Starting From Zero, 10.

${ }^{20}$ In Indefensible Space, Sorkin describes it thus: "Ground Zero - the null site - is the be refilled with numbers and lists: the enumerated names, the 1776 foot tall freedom tower, the solar azimuth of the wedge of light, the 125 conserved column stubs. But there are other numbers that are, perhaps, of greater consequence and the synesthesia of these real, hard, numbers with the constant fluctuations of the symbolic or imaginary numbers of commemoration established the numeracy of meaning that defines both place and event, a mathematics differentially equated. The prime number, the one number that would not budge-even as the casualty count and reconstruction costs rose and fell-was the 10 million square feet of 'space' lost on 9/11." Sorkin, Indefensible Space, 222.

${ }_{21}^{2}$ In Staring From Zero, Sorkin relates a story of a discussion about the families of the "disappeared" in Argentina to illustrate his belief that the project at Ground Zero should take on a form that would emphasize its commemorative nature. Sorkin, Starting From Zero, 8-9.

${ }^{22}$ The response of the public and various grassroots interest groups (including those of survivors and families) was one of the most notable characteristics about the competition to redevelop the World Trade Centre site. Sorkin discusses these groups and their role in Starting From Zero and After the World Trade Centre. See, in particular, the chapter, "Thinking Inside the Box." Sorkin, Starting From Zero, 56-61.

${ }^{23}$ Gini index is used by the World Bank as a measure of wealth distribution. It measures the extent to which the distribution of income or consumption expenditure among individuals or households within an economy deviates from a perfectly equal distribution. "Gini Index," The World Bank, http://data.worldbank.org/indicator/SI.POV.GINI

${ }^{24}$ The current commissioner of the New York City Department of Transportation (DOT) is Janette Sadik-Khan. Under her leadership, the DOT has implemented a number of initiatives, including "the creation of Broadway Boulevard, the commencement of new bus routes in the Bronx, Manhattan and Staten Island, the installation of 23 plazas, the addition of 285 miles of bike lanes, and the organization of car-free summer streets," etc. In 2008, it also published its strategic plan: Sustainable Streets (http://www.nyc.gov/html/dot/html/about/commbio.shtml).

${ }^{25}$ In Giving Ground, Sorkin makes the same point about the city of Los Angeles which, he notes, dedicates one third of its land area to the car. He sees this as a manifestation of what he calls "auto-eroticism." Michael Sorkin and Joan Copjec, Giving Ground: The Politics of Propinquity (New York: Verso, 1999), 9.

${ }^{26}$ In Indefensible Space, Sorkin writes: "When finally rebuilt Ground Zero will hold one of the planet's most intense concentrations of surveillance and police technologies: hyper visibility - submission to continuous screening and profiling by the 'authorities' - will be the condition of entry to the site. Ground Zero will be an intensified, idealized, highly legitimated version of a more generally pervasive environment, the utopia - the Disneyland of Fear. It will provide the icon to fulfill and justify Kallstrom's prophecy." Sorkin. Indefensible Space, 216.

${ }^{27}$ In Starting From Zero, Sorkin describes "paranoia" as a growth industry and suggests that we run the risk of "acquiescing in the re-imagination of our cities as battlegrounds, rushing to superimpose military order in a place that requires very different styles of discipline, hierarchy, and choice." Sorkin, Starting From Zero, 114-115.

${ }^{28}$ Protestors were eventually evicted from Zuccotti Park by police in November 2011, after a court order granted the City permission to "legally" evict the protestors. Mayor Michael Bloomberg justified the action on the grounds of health and safety, on the one hand, and by arguing that the protest was making the park "unavailable to anyone else." When reopened, new regulations were in place that prevented protestors from staying overnight and camping. James Barron and Colin Moynihan, "City Reopens Park After Protesters Are Evicted,” New York Times,November 15, 2011, http://www.nytimes.com/2011/11/16/nyregion/police-begin-clearing-zuccotti-park-of-protesters.html

${ }^{29}$ Sorkin discusses this in more detail in Indefensible Space, vii 
${ }^{30}$ In an essay entitled "Architecture Emblematic; Hardened Sites and Softened Symbols," Trevor Boddy discusses various examples of "architectural intentions" intended to create an "image" of security but which in reality offer little, if any, security against a determined terrorist attack. As a result, he reads this architecture in purely symbolic and even propagandistic terms. Trevor Boddy, "Architecture Emblematic: Hardened Sites and Softened Symbols," in Indefensible Space: The Architecture of the National Insecurity State, ed. Michael Sorkin (New York: Routledge, 2007), 278-304.

${ }^{31}$ Thomas Frank is a cultural historian, author, and journalist. He has focused on American electoral politics, advertising, journalism, and economics. He has become increasing critical of conservative politics in the United States. In What's the Matter with Kansas? How Conservatives Won the Heart of America, he puts forward a thesis that suggests that the political and media systems in the United States focus attention on "hot" social issues such as abortion and gay marriage as a way of energizing the support of a socially conservative electorate that is, to all intents and purposes, distracted from considering issues such as the economy and heath care. Thomas Frank, What's the Matter with Kansas? How Conservatives Won the Heart of America (New York: Holt Paperbacks, 2004).

${ }^{32}$ In Some Assembly Required, Sorkin discusses the relationship between the Cold War, the climate of fear it was used to generate, and the construction of the U.S. interstate highway system, literally called the National Defense Highway System. One of the urban developments to emerge along with the highway system was, of course, suburbia - a theme he has discussed alongside the development of Disney World and its intended New Town: EPCOT. See: Sorkin. Some Assembly Required, 223; Variations on a Theme Park, 224-226.

${ }^{33}$ The biography to which Sorkin refers is: Jon Meacham, Thomas Jefferson: The Art of Power (New York: Random House, 2012). In the same year, there was also another book about Jefferson published in the United States that dealt with his attitudes and actions with regard to slavery: Henry Wiencek, Master of the Mountain: Thomas Jefferson and His Slaves (New York: Farrar, Straus and Giroux, 2012).

${ }^{34}$ The National Housing Institute, founded in 1975, has published various papers dealing with the housing policy and legacy of these administrations. In "Reagan's Legacy: Homelessness in America," Peter Dreier argues that Reagan ignored social and housing issues during both his terms for the simple reason that his electoral base was neither urban nor "the poor." By the end of Reagan's term in office, Dreier suggests that "federal assistance to local governments was cut $60 \%$," and that the only "urban" program that survived the cuts was federal aid for highways - which primarily benefited suburbs, not cities". http://www.nhi.org/online/issues/135/reagan.html The National Housing Institute (NHI), founded in 1975, is "an independent nonprofit organization dedicated to fostering decent, affordable housing and a vibrant community for everyone". http://www.nhi.org/

${ }^{35}$ The HOPE VI Program was developed as a result of recommendations made in the early 1990s by the National Commission on Severely Distressed Public Housing. The program was originally known as the Urban Revitalization Demonstration (URD). It supplies funding and support to any Public Housing Authority that has severely distressed public housing units in its inventory. It deals with three broad areas: "physical improvements, management improvements, and social and community services to address resident needs." "HOPE VI - Public and Indian Housing - HUD," U.S. Department of Housing and Urban Development.

http://portal.hud.gov/hudportal/HUD?src=/program_offices/public_indian_housing/programs/ph/hope6

${ }^{36}$ In Some Assembly Required, Sorkin describes Reaganville thus: "With its reflective veneration of tradition and its preferences for historical stylings and the forms of the pre-industrial city, architecture post-modernism was undergirded by a very different set of political assumptions by those of the progressive preservationists. Implicitly and often explicitly this backward looking urbanism evoked and celebrated the putative social relations of 'simpler' times, a monochrome, paternalistic vision of un-alienated labor in an unpressured environment: Reaganville." Sorkin, Some Assembly Required, 3

${ }^{37}$ Sorkin begins Variations on a Theme Park by quoting Walter Wristen, a former CEO of the Citicorp, who declared, "the 800 telephone number and the piece of plastic have made time and space obsolete." For Sorkin, technologies such as mobile phones and the Internet are "instruments of instant artificial adjacency [that] are rapidly eviscerating historic politics of propinquity, the very cement of the city." He suggests that they give rise to "a wholly new kind of city; a city without a place attached to it." Sorkin, Variations on a Theme Park, xi.

${ }^{38}$ Sorkin discusses New Urbanism in his essay, “Acting Urban.” In this essay, he suggests that whilst New Urbanism may reduce car use within the suburbs, it completely fails as "social ecology" by inducing increased homogenization of attitudes and behaviours through its building laws and codes of conduct. Sorkin, "Acting Urban," in Some Assembly Required, 64-69.

${ }^{39}$ Another term Sorkin uses to describe this phenomena is the "ageographical" city. Sorkin, Variations on a Theme Park, xi. 


\section{Bibliography}

Aerts, Jeroen C. J. H., and W. J. Wouter Botzen. Flood-Resilient Waterfront Development in New York City: Bridging Flood Insurance, Building Codes, and Flood Zoning. Boston, Mass.: Blackwell Publishing, 2011.

Boddy, Trevor. "Architecture Emblematic; Hardened Sites and Softened Symbols." In Indefensible Space: The Architecture of the National Insecurity State, edited by Michael Sorkin, 278-304. New York: Routledge, 2007.

Chance, Julia, and Torsten Schmiedeknecht, eds. Fame and Architecture. London: John Wiley and Sons, London, 2001

The City of New York. "NYC DOT - Commissioner Janette Sadik-Khan." http://www.nyc.gov/html/dot/html/about/commbio.shtml

Flint, Kevin J., and Nick Peim. Rethinking the Education Improvement Agenda: A Critical Philosophical Approach. London: Continuum, 2012.

Frank, Thomas. What's the Matter with Kansas? How Conservatives Won the Heart of America. New York: Holt Paperbacks, 2004.

Herman, Edward S., and Noam Chomsky. Manufacturing Consent: The Political Economy of the Mass Media. 2nd ed. New York: Pantheon Books, 2002.

Jose, Katherin. "How 'The New York Times' Controls Architecture Criticism in America, Whoever Its Critics May Be." Capital. March 1, 2012. http://www.capitalnewyork.com/article/culture/2012/03/5376996/how-new-york-times-controlsarchitecture-criticism-america-whoever-i

The National Housing Institute (NHI). "Reagan's Legacy: Homelessness in America.” http://www.nhi.org/online/issues/135/reagan.html

Simon, Bryant. Everything But the Coffee: Learning About America from Starbucks. California: University of California Press, 2009.

Sorkin, Michael, and Joan Copjec, eds. Giving Ground: The Politics of Propinquity. New York: Verso, 1999.

Sorkin, Michael, and Sharon Zukin. After the World Trade Center: Rethinking New York City. New York: Routledge, 2002.

Sorkin, Michael. Exquisite Corpse: Writing on Buildings. New York: Verso, 1991.

---. Twenty Minutes in Manhattan. New York: Reaktion Books, 2009. 
---. Variations on a Theme Park: The New American City and the End of Public Space. New York: Hill \& Wang, 1992.

---. Local Code: The Constitution of a City at 42 Degrees North Latitude. New York: Princeton Architectural Press, 1996.

---. Some Assembly Required. Minneapolis: University of Minnesota Press, 2001.

---. The Next Jerusalem. New York: Monacelli, New York, 2002.

---. Indefensible Space: The Architecture of the National Insecurity State. New York: Routledge, 2007.

---. Starting From Zero. New York: Routledge, 2003.

---. Michael Sorkin Studio: Work in Progress Series. New York: Monacelli Press, 1998.

U.S. Department of Housing and Urban Development. "HOPE VI - Public and Indian Housing - HUD." http://portal.hud.gov/hudportal/HUD?src=/program_offices/public_indian_housing/programs/ph/hope6

Watson, Robert P., and Douglas M. Brattebo, eds. The Obama Presidency: A Preliminary Assessment. New York: Suny Press, 2012. 